\title{
Identification and Evaluation of Human Errors in Locomotive Maneuvers Using the SHERPA Technique: A Case Study in a Rail Operation Repair and Development Project
}

\author{
Fatemeh Karami $^{1}$ (D), Samira Ghiyasi ${ }^{2 *(1 D)}$, Ahmad Soltanzadeh ${ }^{3}$
}

1. MSc in HSE, Department of Environmental Engineering, Central Tehran Branch, Islamic Azad University, Tehran, Iran

2. Assistant Professor, Department of Environmental Engineering, Central Tehran Branch, Islamic Azad University, Tehran, Iran

3. Assistant Professor, Department of Occupational Health Engineering and Occupational Safety, Environmental Pollutants Research Center, School of Health, Qom University of Medical Sciences, Qom, Iran

\begin{tabular}{|c|c|}
\hline Article Info & ABSTRACT \\
\hline $\begin{array}{l}\text { Received: 2020/09/08; } \\
\text { Accepted: } 2020 / 12 / 28 ; \\
\text { ePublished: } 2020 / 12 / 28 \\
\text { doi } \frac{\text { 10.30699/jergon.8.4.1 }}{\text { Use your device to scan }} \\
\text { and read the article online } \\
\text { Q }\end{array}$ & $\begin{array}{l}\text { Background and Objectives: Despite complex technologies in many work } \\
\text { environments, human errors are of great importance as they might lead to severe and } \\
\text { catastrophic accidents. Therefore, in order to prevent and limit the consequences of } \\
\text { human error, it seems necessary to identify and find the causes of them. The aim of } \\
\text { this study was to identify and evaluate the human errors of locomotive maneuvers in } \\
\text { the railway repair and development project, } 2019 \text {. } \\
\text { Methods: In this cross-sectional study, the identification and evaluation of } \\
\text { human errors in locomotive maneuvers in the MAPNA railway repair and } \\
\text { development project using SHERPA technique was done. First, using the hierarchical } \\
\text { task analysis method, the activities of the maneuvers were divided into their tasks } \\
\text { and sub-tasks; in the next step, the types of human errors in each of the tasks were } \\
\text { identified and then human errors were evaluated according to SHERPA instruction. }\end{array}$ \\
\hline $\begin{array}{l}\text { Corresponding Author } \\
\text { Samira Ghiyasi } \\
\text { Assistant Professor, Department of } \\
\text { Occupational Safety \& Hygiene } \\
\text { Engineering, Research Center for } \\
\text { Environmental Pollutants, Faculty } \\
\text { of Health, Qom University of } \\
\text { Medical Sciences, Oom, Iran }\end{array}$ & $\begin{array}{l}\text { Results: A total of } 206 \text { errors were identified in the present study. Errors included } \\
48.5 \% \text { action error, } 39.8 \% \text { checking error, } 10.2 \% \text { information communication error } \\
\text { and } 1.5 \% \text { selection error. The lowest and highest errors related to locomotive } \\
\text { displacement error were related to hot single diesel }(14.0 \%) \text { and locomotive } \\
\text { displacement error on service pit }(29.6 \%) \text {. Of the identified errors, } 23.8 \% \text { had an } \\
\text { unacceptable risk level, } 51.1 \% \text { had an ALARP risk level and } 25.2 \% \text { had an } \\
\text { acceptable risk level. }\end{array}$ \\
\hline $\begin{array}{l}\text { Email: } \\
\text { s.ghiasi@iauctb.ac.ir }\end{array}$ & $\begin{array}{l}\text { Conclusion: The findings of the study indicated that the most unacceptable risks } \\
\text { and ALARP were related to checking and action error, respectively. So, it is } \\
\text { suggested that the design and implementation of control measures related to these } \\
\text { two types of errors should be prioritized. }\end{array}$ \\
\hline
\end{tabular}

Keywords: Human error, SHERPA technique, Accident, Locomotive maneuver

Copyright (C) 2021, This is an original open-access article distributed under the terms of the Creative Commons Attribution-noncommercial 4.0 International License which permits copy and redistribute of the material just in noncommercial usages with proper citation.

\section{How to Cite This Article:}

Karami F, Ghiyasi S, Soltanzadeh A. Identification and Evaluation of Human Errors in Locomotive Maneuvers Using the SHERPA Technique: A Case Study in a Rail Operation Repair and Development Project. Iran J Ergon. 2020; 8 (4) :1-14 


\section{Extended Abstract}

\section{Introduction}

Despite complex technologies in many work environments, human errors are of great importance as they might lead to severe and catastrophic accidents. Therefore, in order to prevent and limit the consequences of human error, it seems necessary to identify and find the causes of them. The aim of this study was to identify and evaluate the human errors of locomotive maneuvers in the railway repair and development project, 2019.

\section{Methods}

In this cross-sectional study, the identification and evaluation of human errors in locomotive maneuvers in the Mapna railway repair and development project using SHERPA technique was done. First, using the hierarchical task analysis method, the activities of the maneuvers were divided into their tasks and sub-tasks; in the next step, the types of human errors in each of the tasks were identified and then human errors were evaluated according to SHERPA instruction.

\section{Results}

A total of 206 errors were identified in the present study. Errors included $48.5 \%$ action error, $39.8 \%$ checking error, $10.2 \%$ information communication error and $1.5 \%$ selection error. The lowest and highest errors related to locomotive displacement error were related to hot single diesel (14.0\%) and locomotive displacement error on service pit (29.6\%). Of the identified errors, $23.8 \%$ had an unacceptable risk level, $51.1 \%$ had an as low as reasonably practicable (ALARP) risk level and $25.2 \%$ had an acceptable risk level.

Table 1. Frequency and percentage of type of errors

\begin{tabular}{|ccc|}
\hline Error type & $\mathbf{N}$ & $\mathbf{\%}$ \\
\hline Operational & 100 & 48.5 \\
\hline Review & 82 & 39.8 \\
\hline Recovery & 0 & 0.0 \\
\hline communicational & 21 & 10.2 \\
\hline Optional & 3 & 1.5 \\
\hline
\end{tabular}

Table 3. Frequency and percentage of risk level of errors studied

\begin{tabular}{ccc}
\hline Risk levels & $\mathbf{N}$ & $\mathbf{\%}$ \\
\hline Acceptable & 52 & 25.2 \\
\hline ALARP & 105 & 51.0 \\
\hline Unacceptable & 49 & 23.8 \\
\hline
\end{tabular}

Table 4. Results of error assessment related to the task of moving the locomotive on the service pit

\begin{tabular}{|ccccc|}
\hline Sub-duty & Error type & Possibility & Intensity & Risk index \\
\hline Get the app from the headmaster & C4 & B & 4 & $4 \mathrm{~B}$ \\
\hline Maneuvering position next to diesel & C1 & D & 4 & $4 \mathrm{D}$ \\
\hline Inspection around diesel & A2 & D & 4 & $4 \mathrm{D}$ \\
\hline Standing on the diesel ladder & C2 & D & 4 & $4 \mathrm{D}$ \\
\hline $\begin{array}{c}\text { Commanding locomotives to be placed on the } \\
\text { service pit }\end{array}$ & C1 & B & 4 & $4 \mathrm{~B}$ \\
\hline
\end{tabular}




\begin{tabular}{|ccc|cc|}
\hline $\begin{array}{c}\text { Sub-duty } \\
\text { Coming down from the diesel to change the } \\
\text { needle }\end{array}$ & Error type & Possibility & Intensity & Risk index \\
\hline Needle replacement & A & A & 3 & $3 \mathrm{~A}$ \\
\hline Riding on diesel & C 3 & C & 1 & $1 \mathrm{C}$ \\
\hline Getting off the diesel & A & B & 3 & $3 \mathrm{~B}$ \\
\hline Ensure that the locomotive is braked & C 2 & B & 4 & $4 \mathrm{~B}$ \\
\hline
\end{tabular}

\section{Discussion}

The results of the present study showed that the SHERPA method, which has been extended to other industries, is suitable for predicting human error in the locomotive maneuver set; because this method was able to well identify and classify the human errors of the maneuvers and reveal the hidden shortcomings of the system $[7,16,17]$. A study conducted to identify human error in cockpit using three methods, SHERPA, HEIST and HUMAN HAZOP, showed that results obtained using SHERPA method in identifying and classifying errors as well as the ability to detect hidden errors, is better than the other two methods. It also suggested using SHERPA method to evaluate human errors in humanmachine systems [18].

Findings of human error assessment using SHERPA technique in the present study indicated that the main amount of identified errors is functional type (48.5\%) which was consistent with previous studies conducted in this field in Iran [16, 21].

Incorrect or incomplete maneuvering command of locomotives by wireless during coupling was reported to be a human error with ALARP risk level in this study. The exchange of correct information is very effective in reducing the likelihood of human error. Therefore, information exchange systems play an important role in this regard.

Based on the observations and findings of human error identification and evaluation in this study, the used communication equipment had technical defects and caused vague communication between maneuvers and locomotives; therefore, by replacing defective wireless and using quality wireless, communication can be done quickly and easily resulting in better accuracy and quality and reducing the incidence of human error and consequent accidents caused by human error.

Evaluation of the study data showed that the errors of locomotive moving tasks on the service pit and changing the direction of the locomotive related to cold diesel have the highest unacceptable level of risk. According to the results of SHERPA technique, the causes of errors with unacceptable level of risk include insufficient maneuverability of the maneuver and locomotives (inconsistency of the number of maneuvering members with what is stated in the general regulations), opening of the diesel end bridge (in Siemens and Steam diesels), lack of maneuver checking during coupling during coupling, the absence or malfunction of the wireless during coupling, the lack of sufficient light during displacement at the site surface and the exit from the hook due to the disconnection of the brake air tube during displacement in cold diesel. Based on the obtained results, control of checking errors (highest percentage of errors with unacceptable risk level) and performance errors (highest percentage of errors with ALARP risk level) should be given priority.

Some of the strategies to control and reduce the risk of human error that have been proposed and considered in the study environment are: training and holding workshops to identify and provide tool box meeting (TBM) for maneuvers and locomotives with the aim of reviewing precontrol systems from moving, compiling instructions and executive methods for maneuvering activities, employing different people for each maneuver in accordance with general rules, replacing defective cords and using 
quality cords, considering people with appropriate physical conditions while working in the service pit, selecting people with Higher accuracy and intelligence, installation of safety and warning signs, improvement of the railway environment, connection of maneuver lines to the sensor and control room, identification of dangerous points of line fractures and correction of these fractures, placing the camera in front of diesels with monitor for locomotives, designing suitable maneuvering position in Siemens locomotive, equipment performance inspection by quality control and control unit, installation of appropriate lighting (optical mast) and design of a safe stand and installation of protection on the platform $[9,22]$.

\section{Conclusion}

The findings of the study indicated that the most unacceptable risks and ALARP were related to checking and action error, respectively. So, it is suggested that the design and implementation of control measures related to these two types of errors should be prioritized.

\section{Acknowledgement}

This article is taken from the master's thesis in Health, Safety and Environmental Management (HSE) at the Islamic Azad University, Central Tehran Branch. The authors express their gratitude to the University's Vice Chancellor for Research as well as the HSE Management, the study participants and the staff of the MAPNA Railway Repair and Development Project.

\section{Conflict of Interest}

The authors declared no conflict of interest. 
مقالة بزووهشى

شناسايى و ارزيابى خطاهاى انسانى مانورجىهاى لكوموتيوها با استفاده از تكنيك SHERPA (مطالعة موردى در :بروزة تعميرات و توسعةُ بجرهبردارى ريلى)

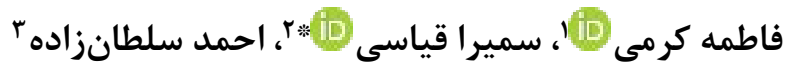

ا . كارشناسى ارشد مديريت بهداشت، ايمنى، محيطزيست (HSE)، كروه مهندسى محيطزيست، دانشكدة فنى و مهندسى، دانشكاه آزاد اسلامى واحد تهران مركزى، تهران، ايران

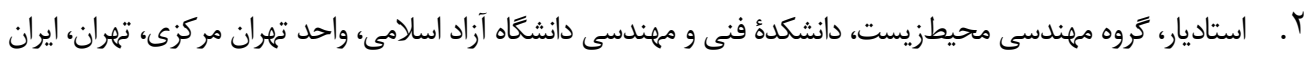

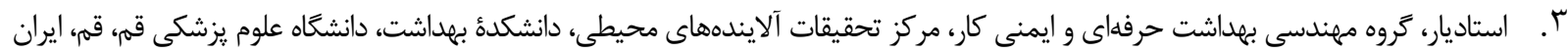

\begin{tabular}{|c|c|}
\hline خلاصه & اطلاعات مقاله \\
\hline 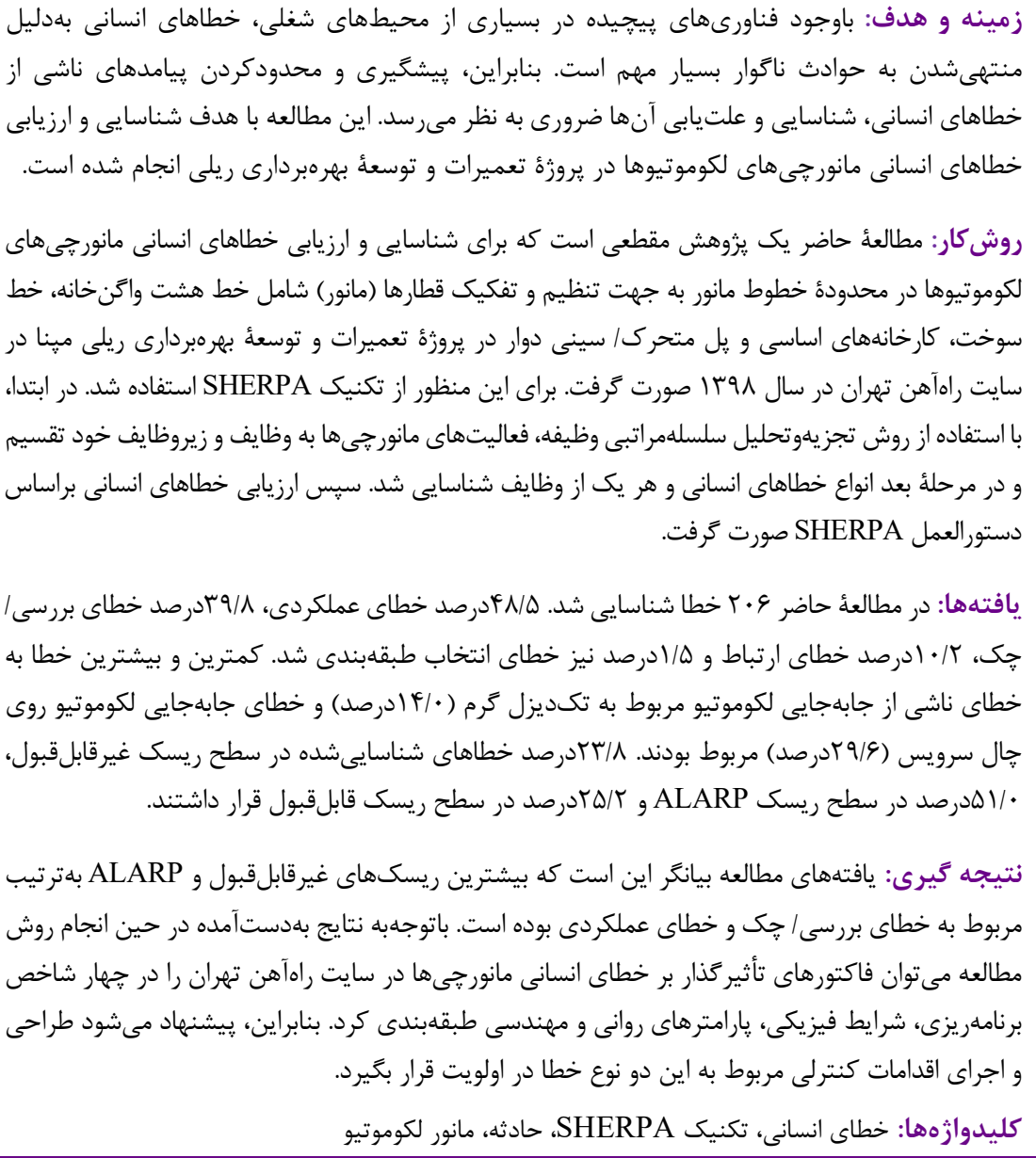 & 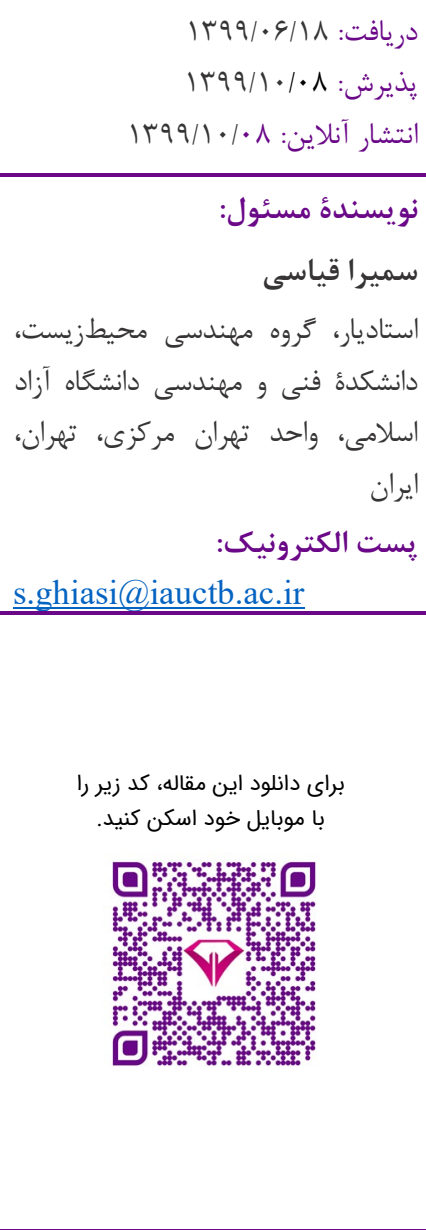 \\
\hline
\end{tabular}

مقدمه

وقوع خطرات ناشى از خطاهاى انسانى در اين فرايندها بالاست. خطاى انسانى شامل انحراف عملكرد انسان از قوانين و وظايف مشخصشده است كه از حد قابلقبول سيستم فراتر برود و بر
المروزه در بسيارى از صنايع سيستمهاى حساس با فيأ

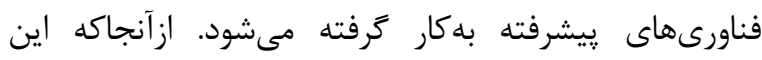
سيستمها همواره در تعامل متقابل با انسانها هستند، يتانسيل 
لكوموتيوهاست. باوجود به كار كيرى فناورى هاى استفادهشه در

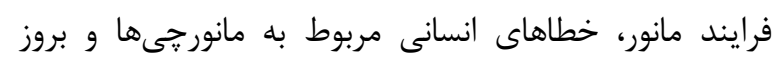

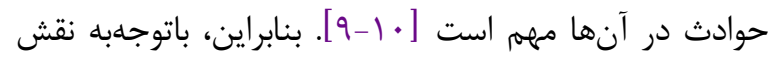

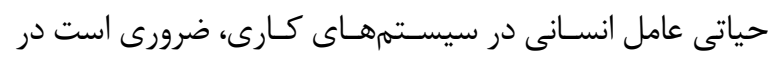

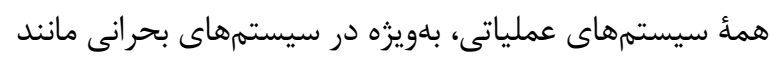

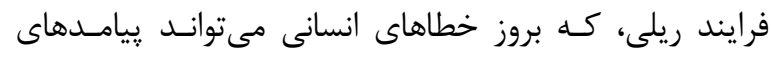

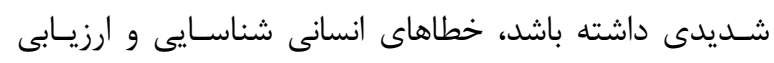
شود و اقدامات كنترلى لازم صور بخيرد تا حوادث و هزينه بـانها

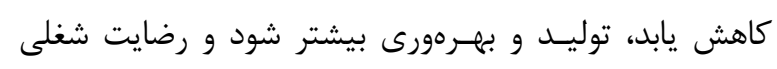

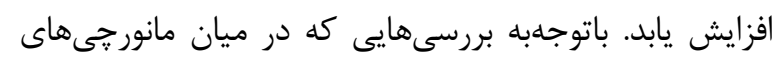

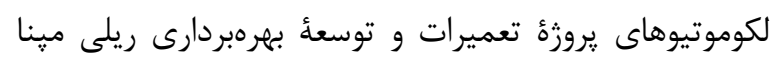

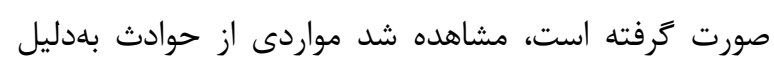

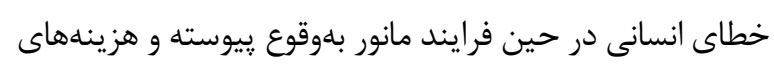

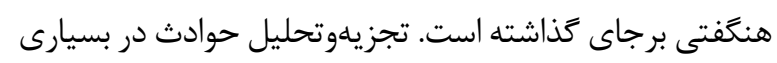

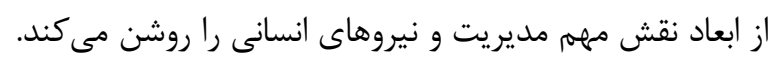

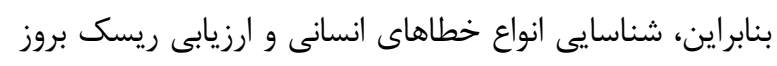

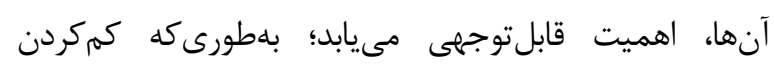

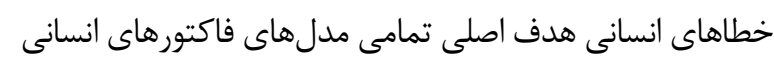

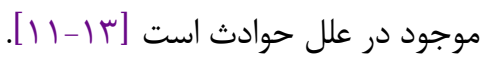
برايناساس، اين مطالعه با هدف شناسايى و ارزيابى خطاى الباى

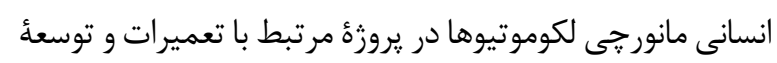
بهرهبردارى ريلى طراحى و اجرا شده است.

\section{روش كار}

مطالعه حاضر يك يزوهش مقطعى است كه براى شناسايى و

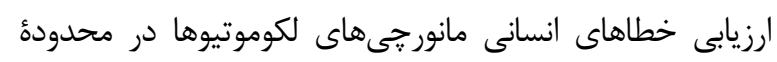
خطوط مانور بامنظور تنظيم و تفكيك قطارها (مانور) شامل خط انط

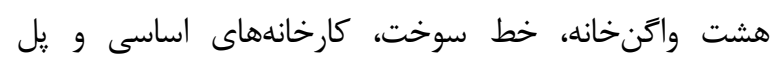

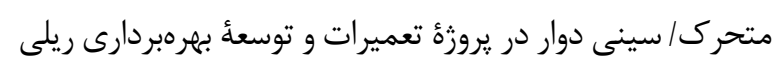

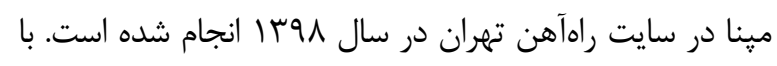

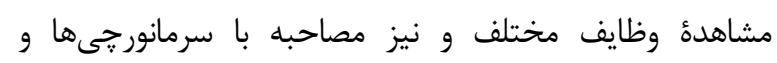

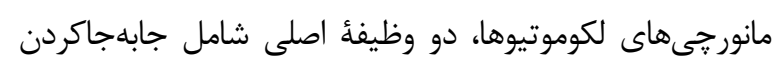

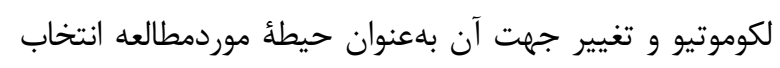

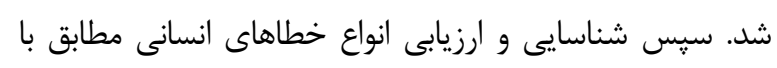
دستورالعمل تكنيك SHERPA صورت كرفت.
كارايى سيستم اثر نامطلوب داشته باشد [ [-r]]. مطالعهُ حوادث

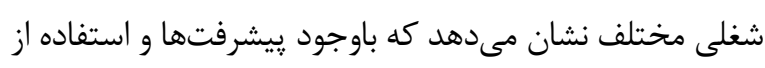

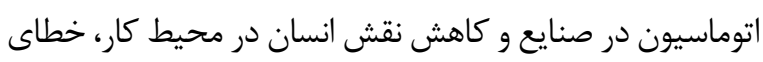

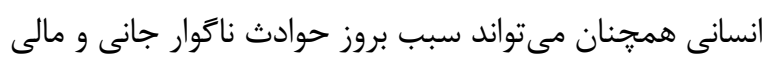

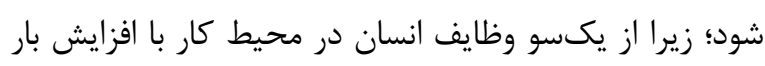

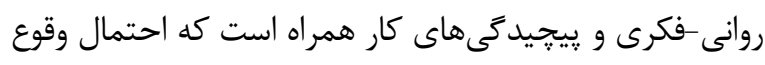

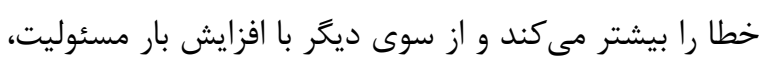

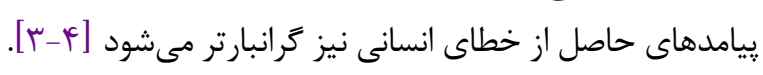

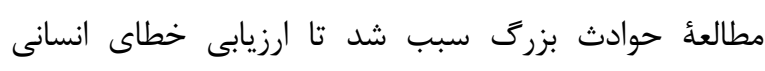

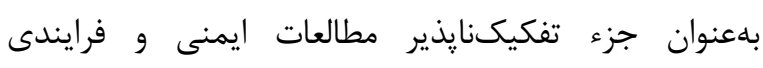
سيستمهاى انسان- ماشين قرار بخَيرد. مدلهاء و تئورى إنهاى

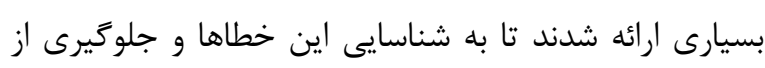
وقوع آنها بيردازند [وك-ه]. مطالعاتى كه تاكنون در زمينهُ خطاى انسانى با روشهاى مختلف صورت گرفته، سيستمهايى را بررسى كردند كه إيراتور

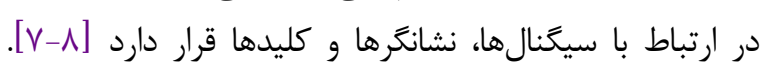
مطالعات محدودى در زمينأ ارزيابى خطاهاى انسانى مانورجى نها

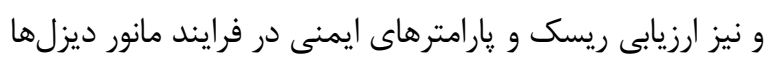
انجام شده است. مانور به حركت هر وسيلة نقليه در دار داخل ايستخاه

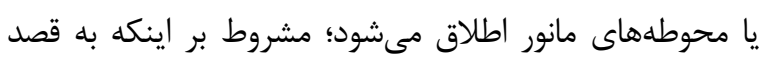

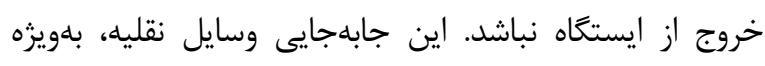

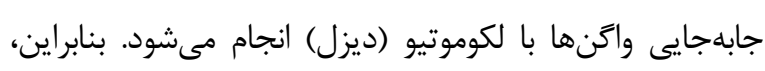

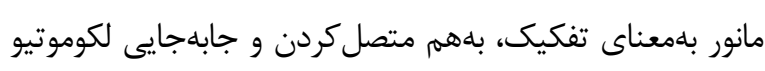

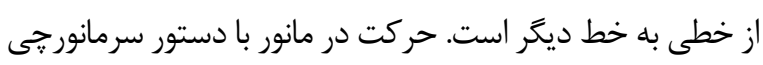

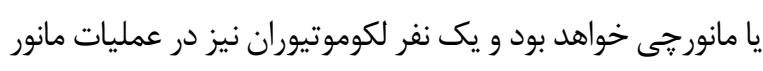

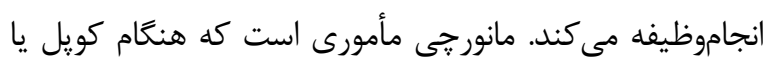

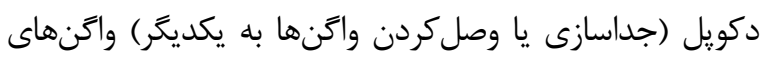

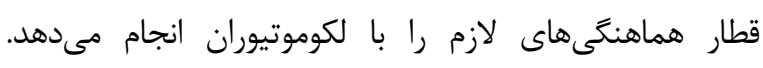

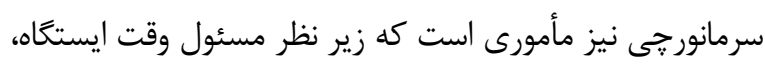

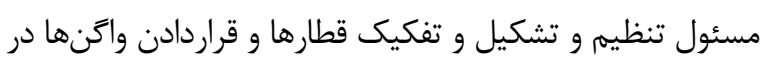

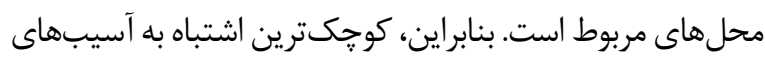

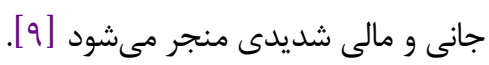

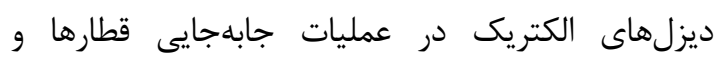

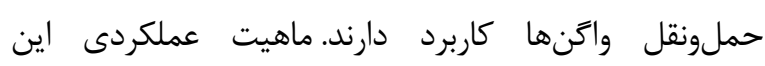

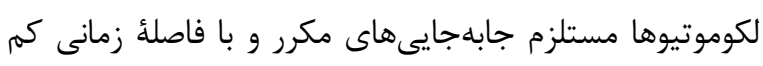
است. ضمناينكه تغيير سريع براى حركت، ديد مناسب رابـ راهبر

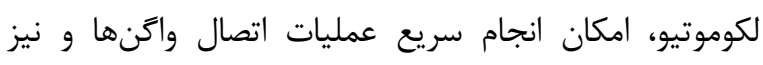

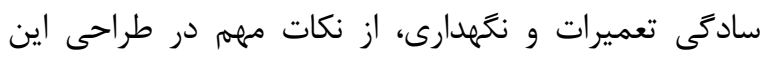


نيروكاههاى هستهاى و برق و ديكر صنايع كاربرد دارد. در اين روش،

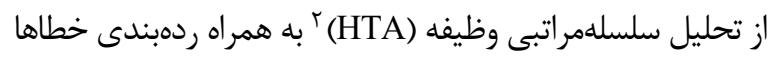
استفاده مىشود. بنابراين، مراحل انجاموظيفه در رفتاريفه آنارهاى كاربر

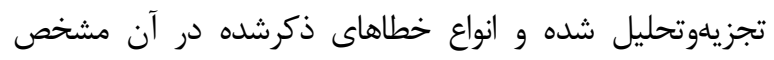

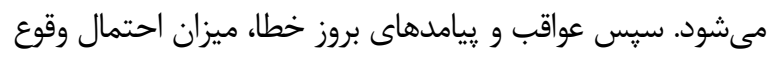

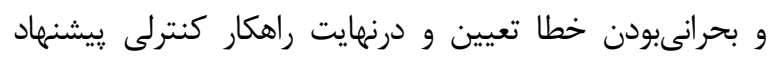

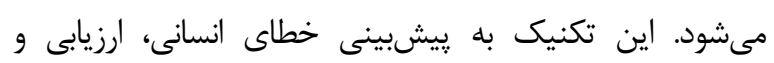

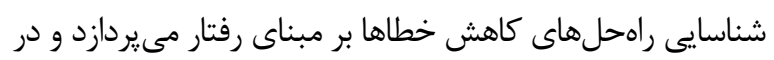

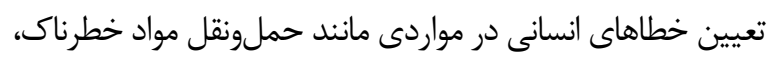

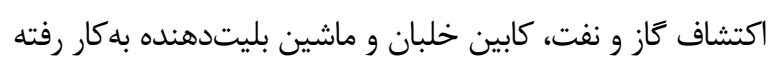

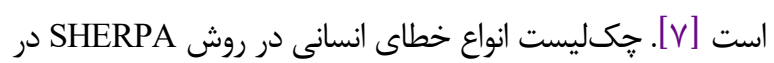
جدول ا ارائه شده است.

\section{تكنيك SHERPA}

رويكرد ييشبينى و كاهش نظاممند خطاى انسانى (SHERPA)

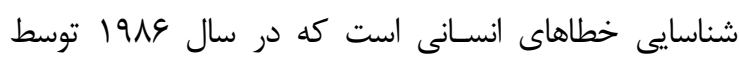

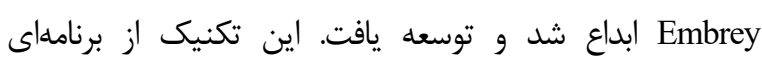

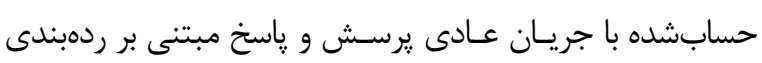

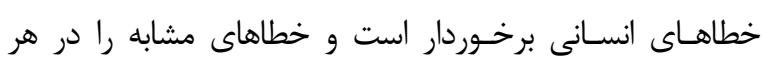

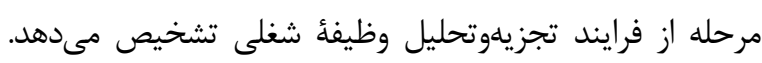
Stanton

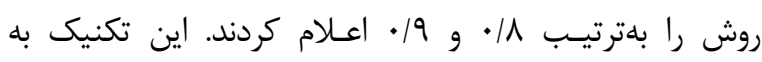

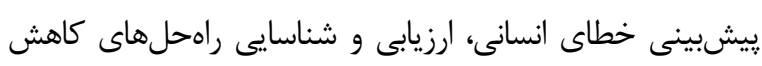

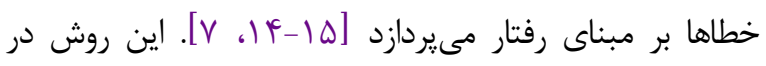
طراحىها و ارزيابى سيستمهاى انسان-ماشين و وِيشبينى

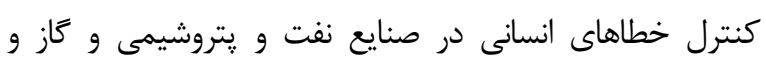

جدول ا. جكليست انواع خطاى انسانى در روش SHERPA

\begin{tabular}{|c|c|c|}
\hline توصيف & شناسهُ خطا & نوع خطا \\
\hline عمل خيلى زود/ دير انجام شود. & A1 & \multirow{10}{*}{ عملكردى } \\
\hline عمل موردنظر بىموقع انجام شود. & $\mathrm{A} 2$ & \\
\hline عمل موردنظر در جهت اشتباه انجام شود. & A3 & \\
\hline عمل كمتر / ييشازحد الزام انجام شود. & A4 & \\
\hline عمل تغيير انجام مىشود. & A5 & \\
\hline عمل صحيح روى گزينأ اشتباه انجام شود. & A6 & \\
\hline عمل اشتباه روى ززينٔه صحيح انجام شود. & A7 & \\
\hline انجام عمل موردنظر فراموش شود. & A8 & \\
\hline عمل، ناقص انجام مىشود. & A9 & \\
\hline عمل اشتباه روى گزينة اشتباه انجام مىشود. & A 10 & \\
\hline 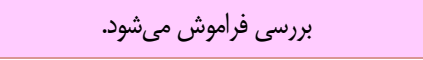 & $\mathrm{C} 1$ & \multirow{6}{*}{ جى / بررسى } \\
\hline بررسى ناقص انجام مىشود. & $\mathrm{C} 2$ & \\
\hline بررسى صحيح روى زَينة اشتباه انجام مىشود. & $\mathrm{C} 3$ & \\
\hline بررسى اشتباه روى گزينة صحيح انجام مىشود. & $\mathrm{C} 4$ & \\
\hline بررسى در زمان نامناسب انجام مىشود. & $\mathrm{C} 5$ & \\
\hline بررسى اشتباه روى كزينُٔ اشتباه انجام شود. & C6 & \\
\hline اطلاعات لازم دردسترس نيست. & $\mathrm{R} 1$ & \multirow{3}{*}{ 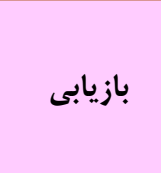 } \\
\hline اطلاعات بلهورت اشتباه ارائه شده است. & $\mathrm{R} 2$ & \\
\hline بازيابى اطلاعات ناقص انجام مىشود. & R3 & \\
\hline
\end{tabular}

${ }^{2}$ Hierarchical Task Analysis
1 Systematic Human Error Reduction \& Prediction Approach 


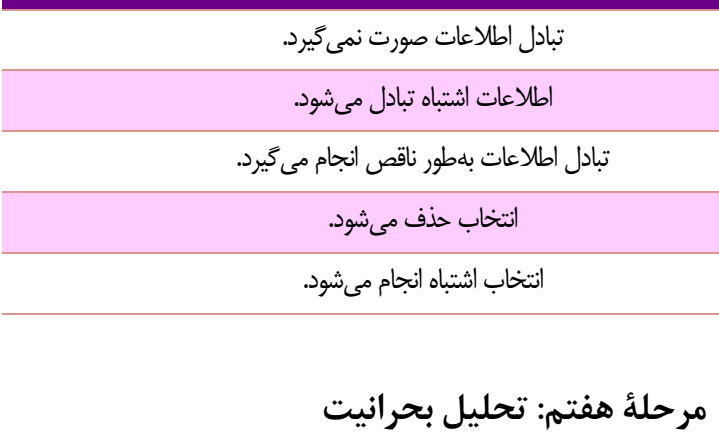

ميزان شدت خسارات ناشى از خطاى انسانى با توجه به ماتريس ريسك گروه مينا تعيين، و از تلفيق آن با احتمال رخداد خطا، سطح ريسك مربوط مشخص شد.

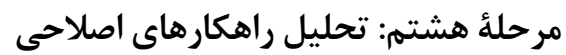

در اين مرحله، راهكارهاى كاهش خطا ارائه شد و مواردى كه

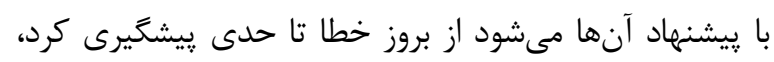
مطرح شد.

يافته ها

با تحليل سلسلهمراتبى وظايف مربوط به مانورجى با

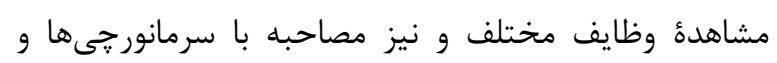
مانورجىهاى لكوموتيوها، دو وظيفهُ اصلى جابهجاكردن لكوموتيو (r وظيفه فرعى) و تغيير جهت لكوموتيو (r وظيفه فرعى) شناسايى شد و زيروظايف هركدام به تفكيك زير

$$
\text { صورت عرفت: }
$$

\section{وظيفهُ جابهجاكردن لكوموتيو تكديزل (ترم):}

دوازده زيروظيفه شامل دريافت برنامه از سرمانورجى، قرارگيرى مانورجى در مجاور ديزل، بازرسى اطراف ديزل (بهمنظور

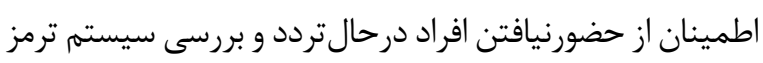
از بيرون)، برداشتن كفش خط (در صورت قرارنخرفتن روى جال

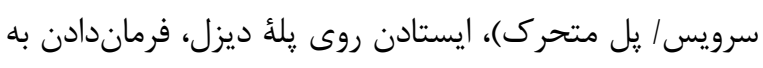

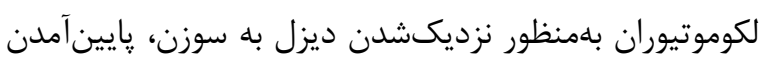

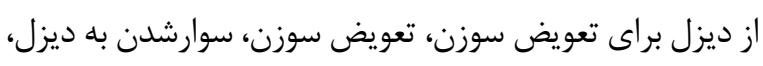

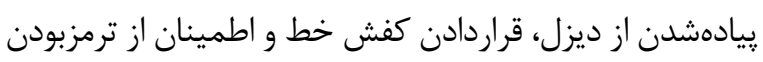

$$
\text { لكوموتيو. }
$$

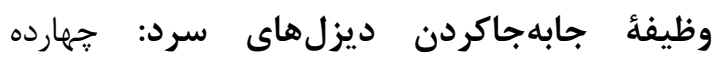
زيروظيفه شامل دريافت برنامه از سرمانورجى، قرارگيرى مانورجى در مجاور ديزل، بازرسى اطراف ديزل (بهمنظور اطمينان از حضورنداشتن افراد درحالتردد و بررسى خرخها درونها ازنظر ترمزنبودن)، برداشتن كفش خط (در صورت قرارنخرفتن

\section{مر احل اجراى مطالعه}

مرحلة اول: تحليل سلسلهمراتبى وظيفه (HTA)

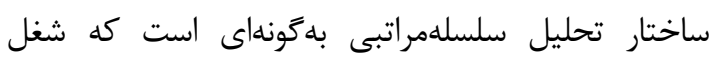
مانورجى به جزئيات و مرتبههاى لازم براى انجام آن تجزيه شده است. در اين روش، وظايف به زيروظيفهها شكسته شده است و و تا آنجا ادامه يافته كه ديخر زيروظيفهاى از آن وظايف باقى وظى نمانده است. در اين يزوهش، دو وظيفه اصلى جابهجاكردن لكوموتيو و تغيير جهت لكوموتيو تعيين و سيس هركدام به زيروظايف خود

$$
\text { تقسيم شدهاند. }
$$

\section{مرحلة دوم: طبقهبندى وظيفه}

هر مرحله از كار از يايينترين سطح تحليل براى طبقهبندى

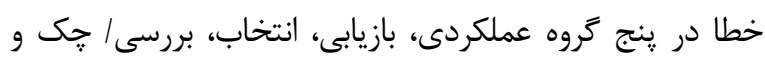

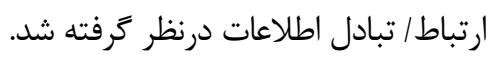

\section{مرحلة سوم: شناسايى خطاى انسانى ربانى}

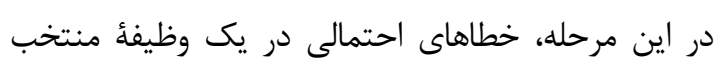
براساس طبقلبندى وظايف انجامشده در مرحله دوم و با استفاده از جكليست انواع خطاهاى انسانى در روش شناسايى شد (جدول (). مرحلة :جهارم: تحليل نتايج بررسى و ارزيابى قييامدهاى هريك از خطاها روى سيستم در اين مرحله صورت مى خيرد. بنابراين، شرح كاملى از نتايج خطاهاى شناسايىشده از مرحله قبل در اين مرحله ارائه شد. مرحله ينجمه: تحليل بازيابى در اين مرحله، يتانسيل سيستم براى يوشش و و كنترل خطاهاى شناسايىشده بررسى شد.

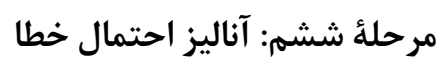
در اين مرحله، احتمال رخداد يك خطا با توجه به ماتريس آنسئ ريسك گروه مينا تعيين شد. در اين ماتريس احتمال وقوع خطا

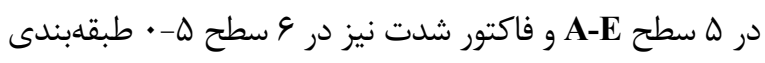
و مشخص شده است. 
به حركتدادن ديزل سرد توسط ديزل گرم براى قراردادن

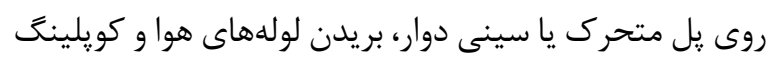

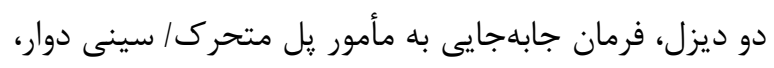

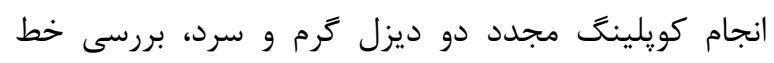

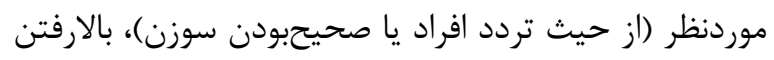
از يلههاى مانورى و دستور حركت به به سمت مقدرد

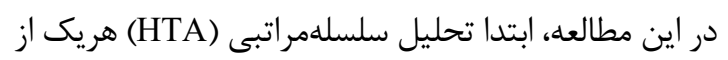

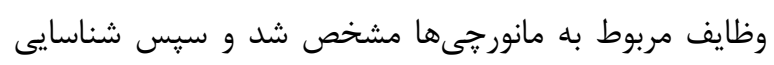

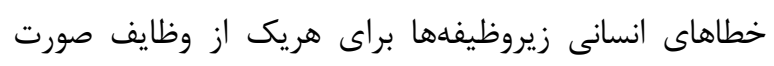

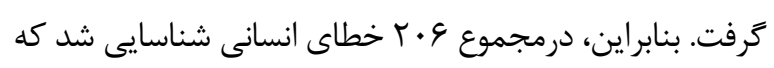

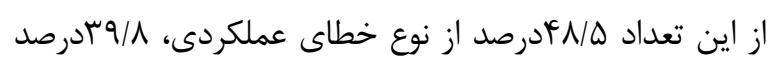

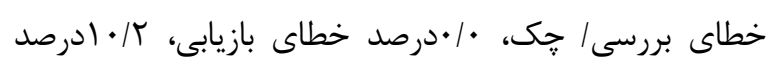

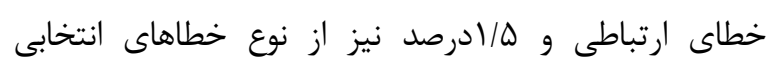
طبقابندى شد (جدول r r). در وظايف مربوط به فعاليتها بلهترتيب خدول) خطاهاى

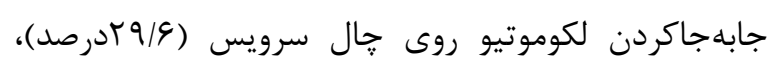

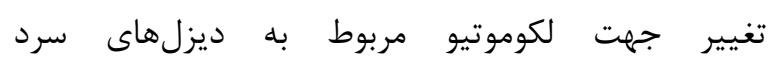

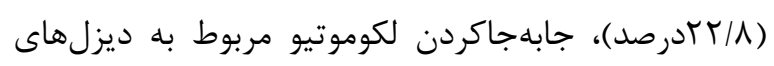

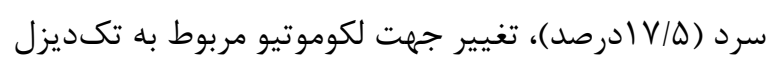

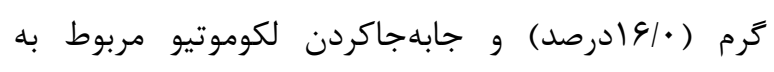

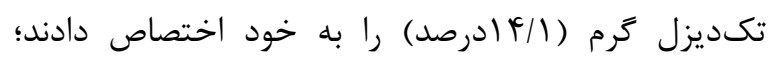

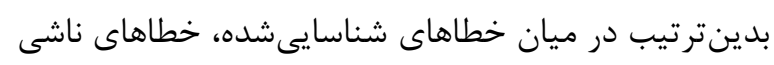

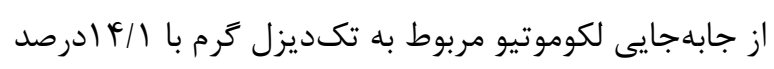

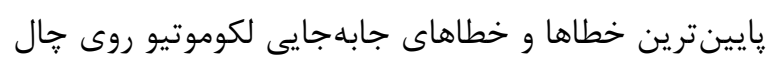

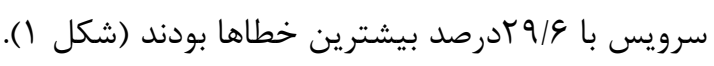

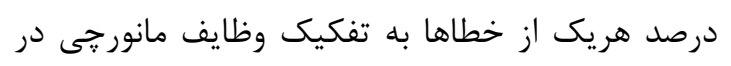

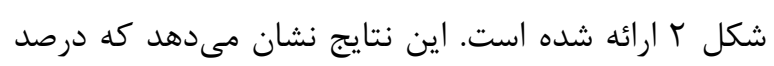
خطاى عملكردى در وظايف جابهجاكردن لكوموتيو روى خال

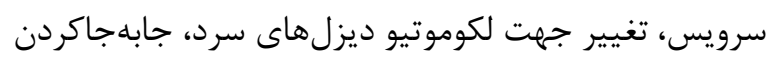
لكوموتيو ديزلهاى سرد، تغيير جهت نهون لكوموتيو تكديزل

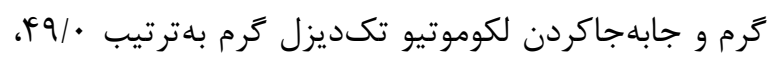

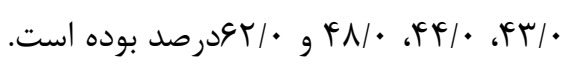

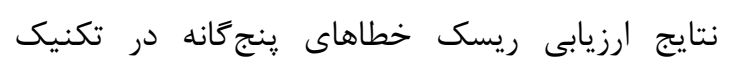

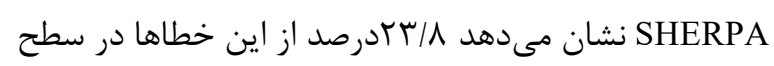

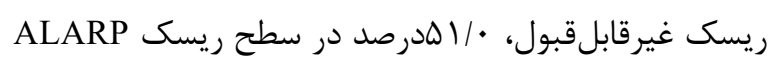

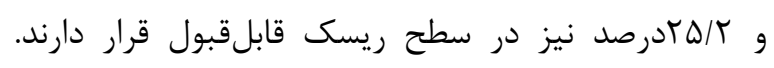

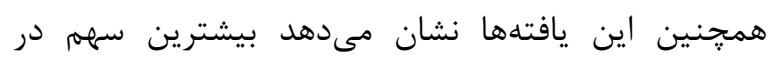

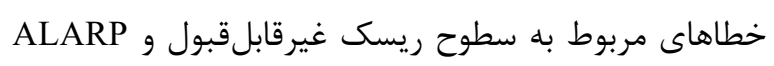

روى جال سرويس/ يل متحرك)، ايستادن روى يلهُ ديزل،

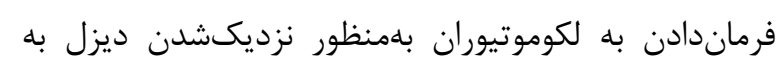

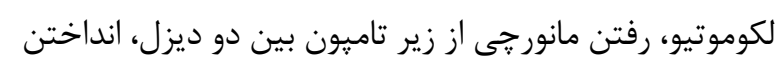

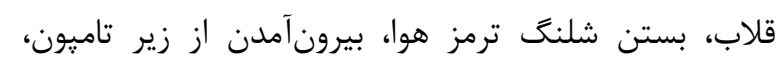

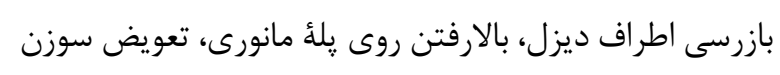
و اطمينان از ترمزبودن لكوموتيو.

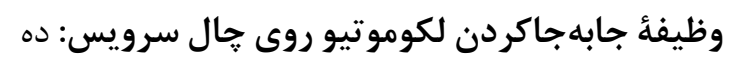

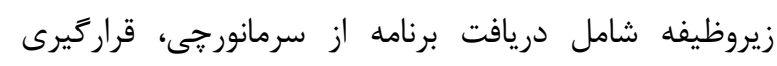

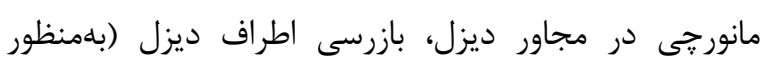

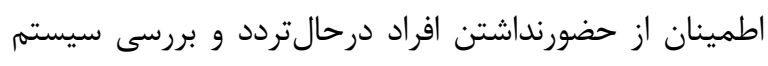

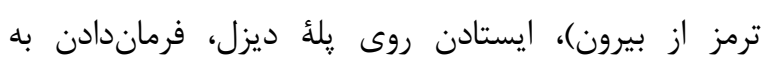

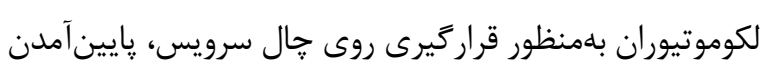

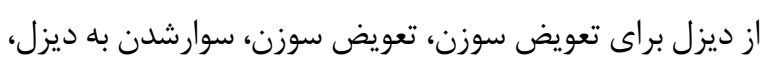

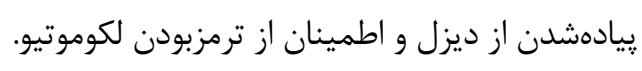

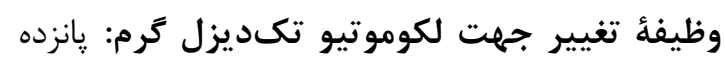

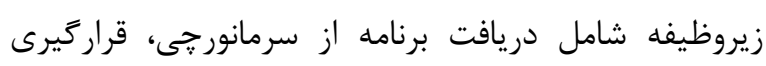

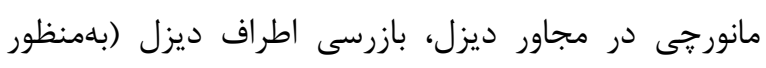

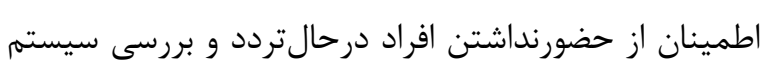

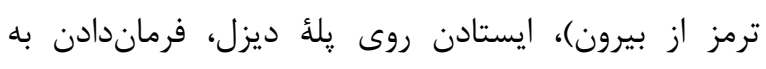

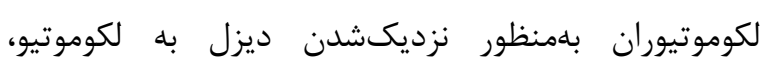

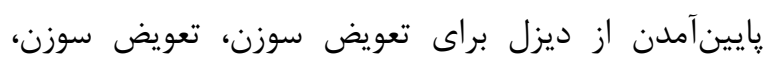

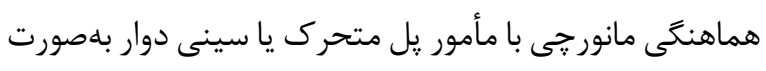

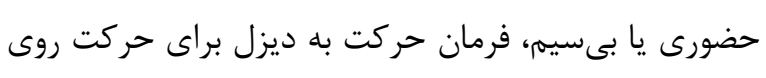

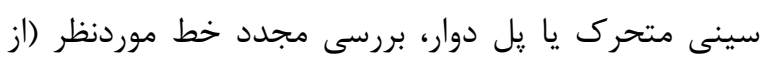

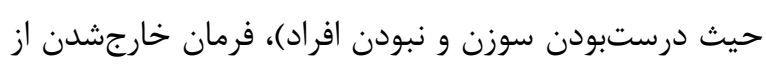

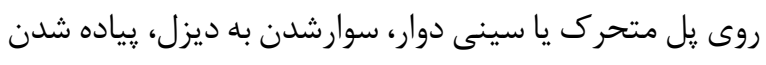

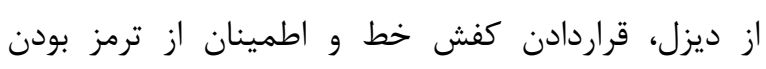
لكوموتيو.

\section{وظيفهُ تغيير جهت لكوموتيو ديزل سرد: بـ ست}

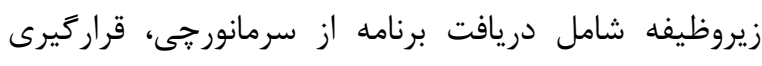

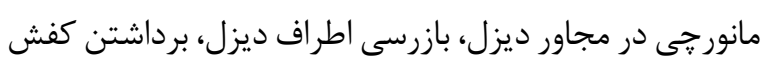

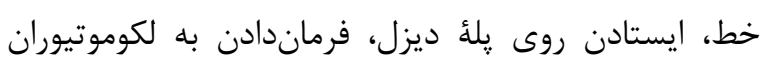

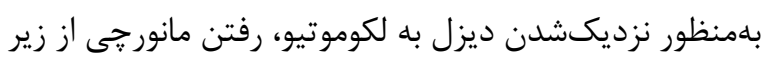

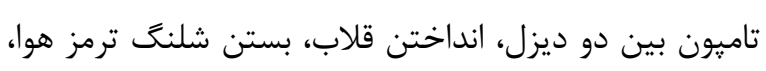

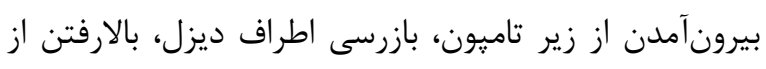

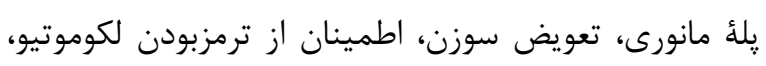

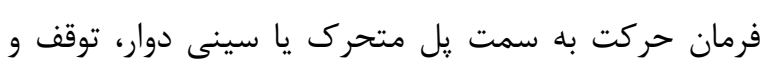

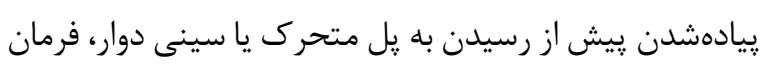


جابهجاكردن لكوموتيو روى حال سرويس در جدول f آمده

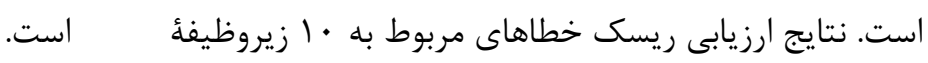

جدول r. فراوانى و درصد نوع خطاها

\begin{tabular}{|c|c|c|}
\hline درصد & تعداد & نوع خطا \\
\hline$\forall \wedge / D$ & $1 \ldots$ & عملكردى \\
\hline$r q / \Lambda$ & NT & بررسى \\
\hline.$\%$ & . & بازيابى \\
\hline $1 \cdot / r$ & rI & ارتباطى \\
\hline $1 / 0$ & r & انتخابى \\
\hline
\end{tabular}
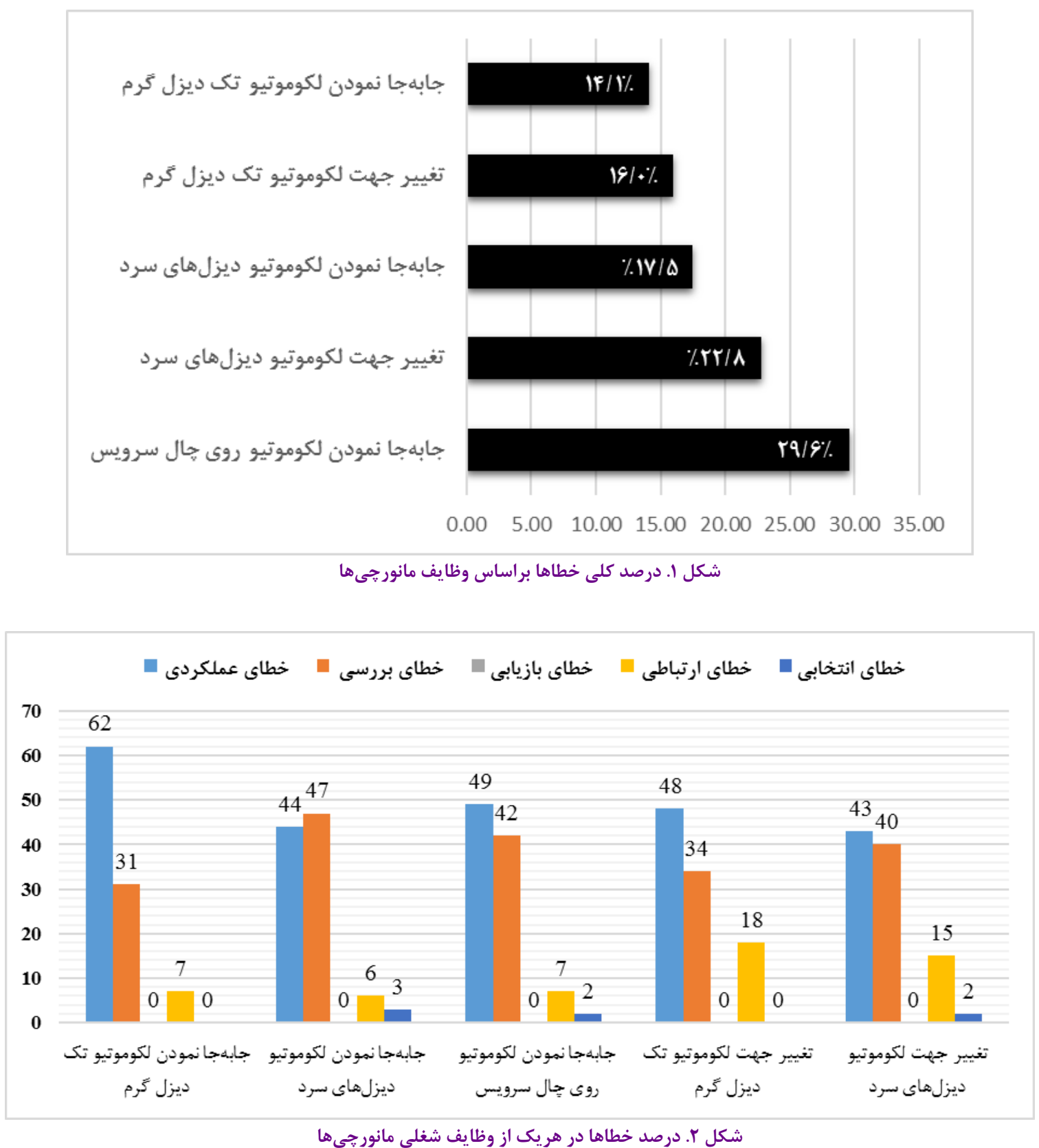
جدول r. فراوانى و درصد سطح ريسك خطاهاى موردمطالعه

\begin{tabular}{|c|c|c|}
\hline درصد & تعداد & سطوح ريسك \\
\hline$r \Delta / r$ & $\Delta r$ & قابلقبول \\
\hline$\Delta 1 / \cdot$ & $1 \cdot 0$ & ALARP \\
\hline rr/A & pq & غيرقابل قبول \\
\hline
\end{tabular}

جدول F. نتايج ارزيابى ريسك خطاهاى مربوط به وظيفهُ جابهجاكردن لكوموتيو روى جال سرويس

\begin{tabular}{|c|c|c|c|c|}
\hline شاخص ريسى & 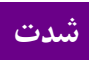 & احتمال & نوع خطا & زيروظيفه \\
\hline $4 \mathrm{~B}$ & 4 & $\mathrm{~B}$ & $\mathrm{C} 4$ & دريافت برنامه از سرمانورجى \\
\hline 4D & 4 & $\mathrm{D}$ & $\mathrm{C} 1$ & قرارگيرى مانورجى در مجاور ديزل \\
\hline $4 \mathrm{D}$ & 4 & $\mathrm{D}$ & A2 & بازرسى اطراف ديزل \\
\hline $4 \mathrm{D}$ & 4 & $\mathrm{D}$ & $\mathrm{C} 2$ & ايستادن روى يلهُ ديزل \\
\hline $4 \mathrm{~B}$ & 4 & $\mathrm{~B}$ & $\mathrm{C} 1$ & فرماندادن به لكوموتيوران بلمنظور قراريّيى روى جال سرويس \\
\hline $3 \mathrm{~A}$ & 3 & A & A6 & يايينآمدن از ديزل جهت تعويض سوزن \\
\hline $1 \mathrm{C}$ & 1 & $\mathrm{C}$ & A2 & تعويض سوزن \\
\hline $1 \mathrm{C}$ & 1 & $\mathrm{C}$ & $\mathrm{C} 3$ & سوارشدن به ديزل \\
\hline $3 \mathrm{~B}$ & 3 & B & A7 & يياددشدن از ديزل \\
\hline $4 \mathrm{~B}$ & 4 & $\mathrm{~B}$ & $\mathrm{C} 2$ & اطمينان از ترمزبودن لكوموتيو \\
\hline
\end{tabular}

بحث

انسان-ماشين براى بيشبينى و كنترل خطاهاى انسانى كارايى

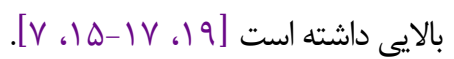

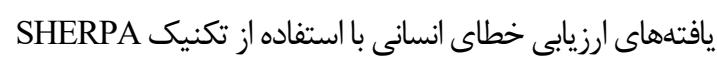
در مطالعه حاضر بيانكر اين بود كه عمدهترين ميزان خطاهاى بائ

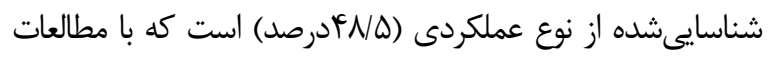

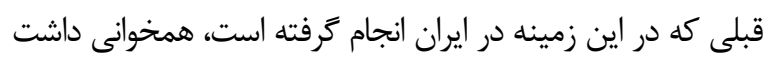

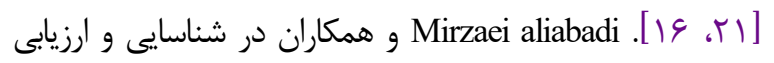
خطاى انسانى در آتش بارى معدن سنگًآهن با استفاده از تكنيك دمانى

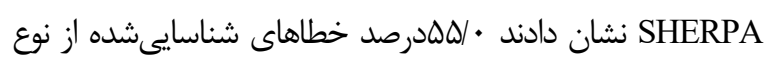

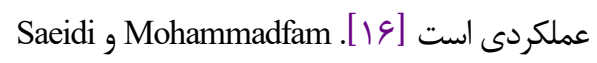
در ارزيابى خطاهاى انسانى در فرايند جراحى آبمرواريد خشم

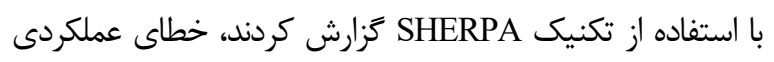
بيش از نيمى از خطاهاى شناسايىشده (94 • لهدرصد) را شامل مىشود [V]. براساس يافتههاى اين مطالعه و نتايج مطالعات ديخر، براى رفع اين مسئلهُ مهم استفاده از دستورالعمل و روش اجرايى ئي مى تواند مؤثر باشد، همجنين ايجاد بستر فرهنگَى مناسب براى انجام كار براساس دستورالعملهاى كارى ايمن از راهكارهاى حذف يا كاهش اين نوع خطاهاست.
نتايج مطالعة حاضر نشان مىدهد روش SHERPA كه در صنايع ديخر گسترش يافته است، براى بيشبينى خطاهاى انسانى

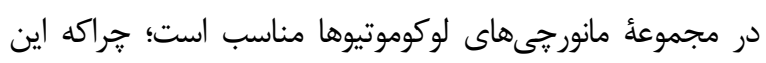
روش توانست بهخوبى خطاهاى انسانى مانورجىها را شناسايى و طبقهبندى كرده و نواقص و كاستىهاى نهان سيستم را آشكار كند

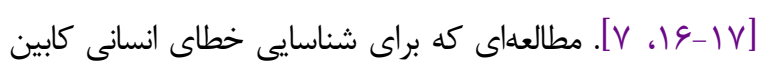
خلبان به سه روش SHERPA, HEIST و HUMAN HAZOP صورت گرفت، روش SHERPA را در شناسايى و طبقلبندى خطاو همجنين قابليت شناسايى خطاهاى ینهان بهتر از دو روش ديخر

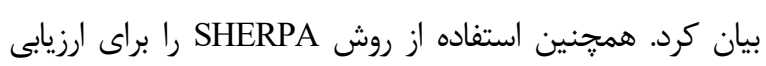

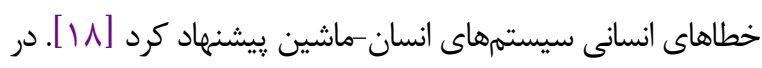
مطالعهاى ديكر كه با استفاده از روش SHERPA به شناسئسيى و ييشبينى خطاهاى انسانى ممكن در طراحى كابين خلبان يرداخته

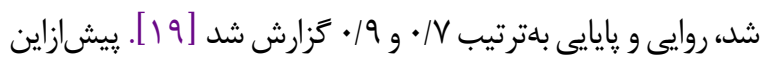
نيز در مطالعهاى يايايى و روايى آمارى روش SHERPA بلهترتيب

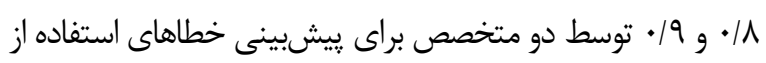

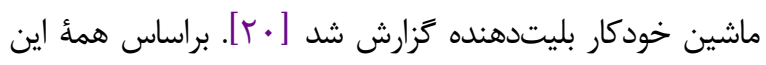
مطالعات، بهكاربردن اين روش در طراحىها و ارزيابى سيستمهاى بـن 
بهسازى محيط راهآهن، اتصال خطوط مانورى به حسكر و اتاق

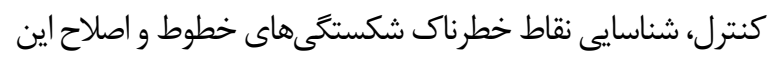

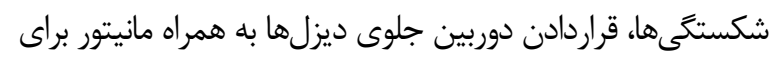

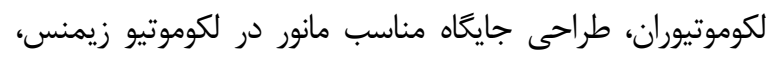
بررسى عملكرد تجهيزات توسط واحد نظارت و كنترل كيفيت، نصب لني روشنايى مناسب (دكل نورى) و طراحى جايكاه ايمن و نصب حست حفاظ

روى سكو [r T، 9].

\section{نتيجه كيرى}

اين يزوهش اولين مطالعه در زمينه بررسى خطاهاى انسانى

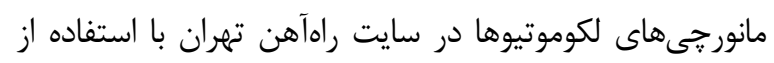

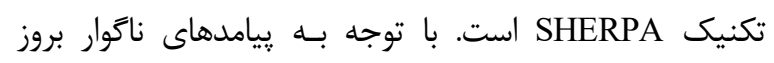

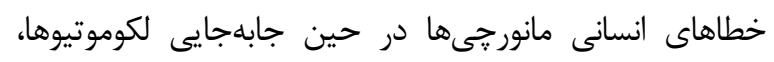

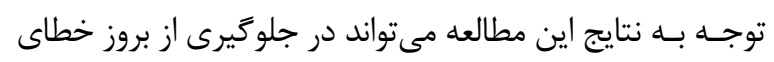

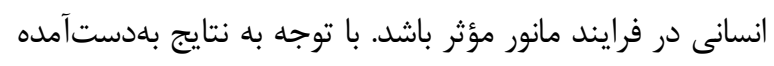

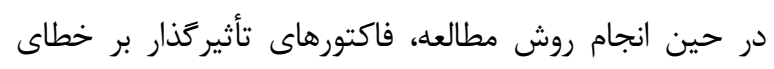

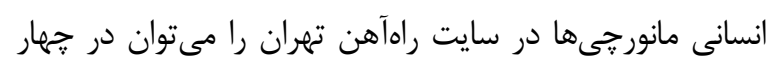

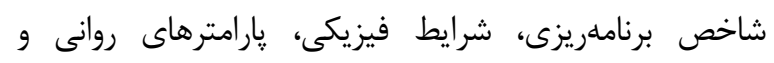

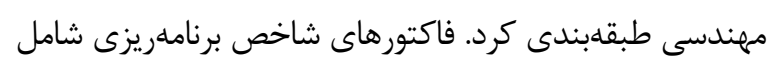

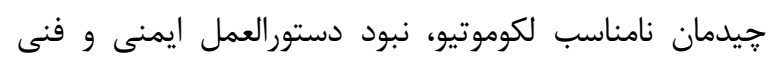

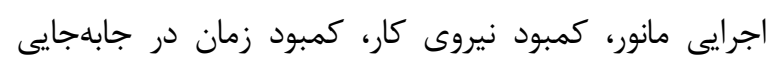

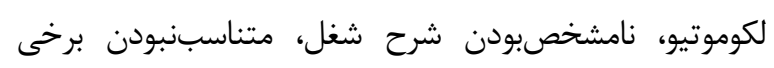

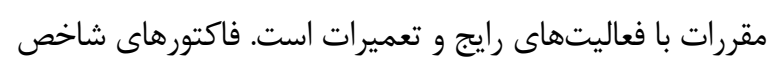
فيزيك شامل شرايط فيزيكى نايمن محيط كاريت فار، شرايط

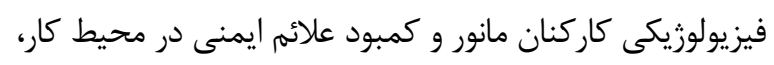

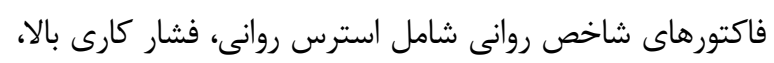

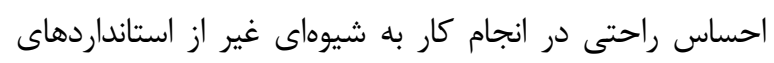

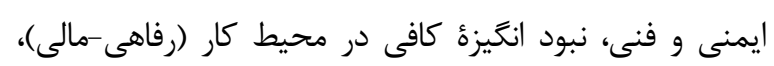

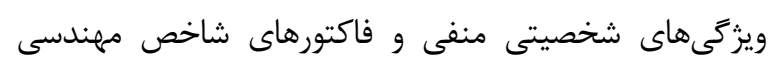
شامل نقص در تجهيزات ارتباطى، نقص در طراحى جايحاه مانور

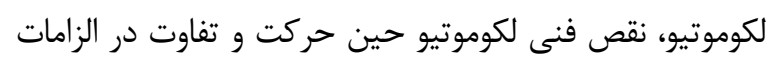
فنى لكوموتيوهاى متفاوت است.

\section{تقدير و تشكر}

اين مقاله بركرفته از קاياننامئ كارشناسى ارشد رشته

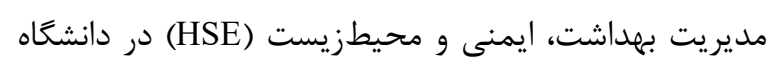

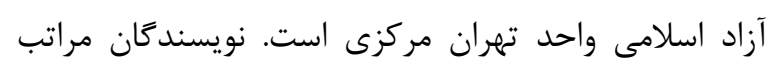

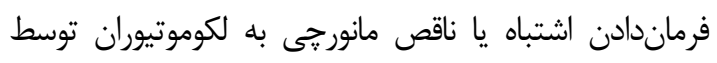

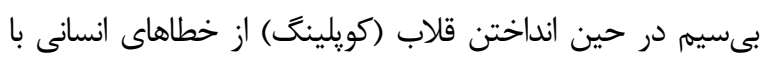
سطح ريسك ALARP در اين مطالعه بود. تبادل اطلاعات صحيح

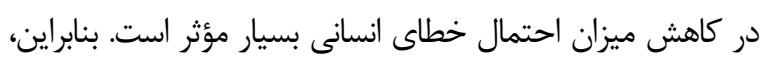

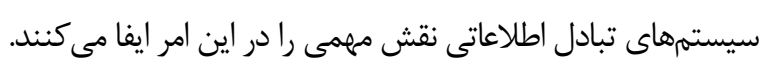

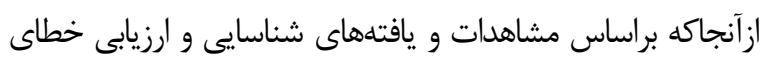

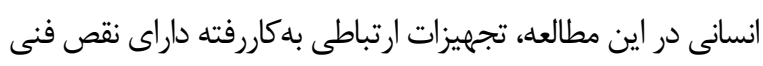
بودند و سبب ارتباطات مبهم بين مانورجىهان و و لكوموتيورانان

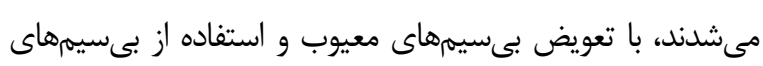

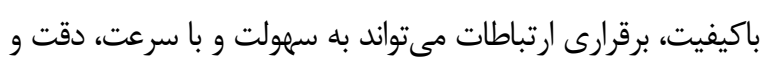

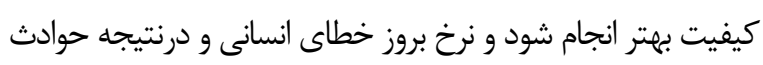

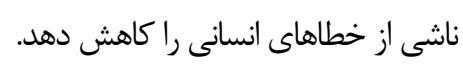

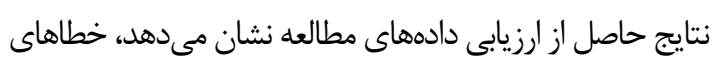
وظايف جابهجاكردن لكوموتيو روى جال سرويس و تنغيير جهت دادي

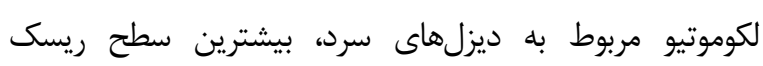

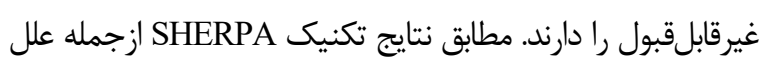

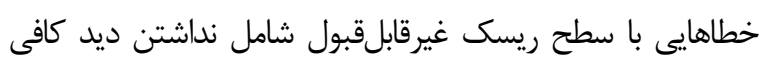

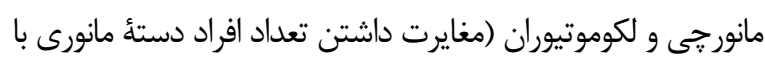

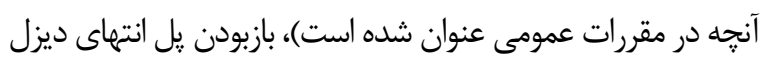

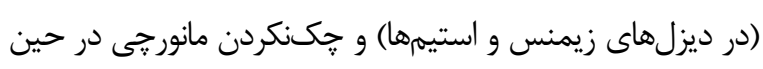

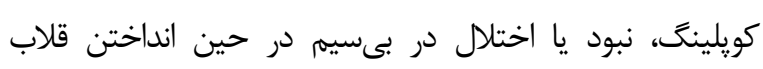

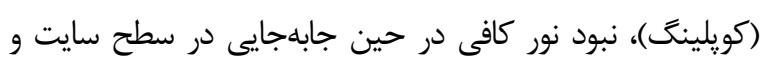

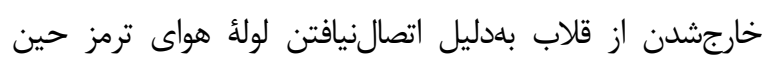

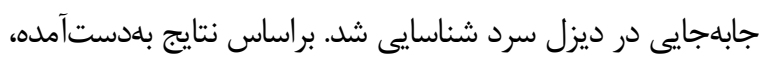

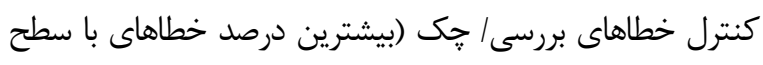

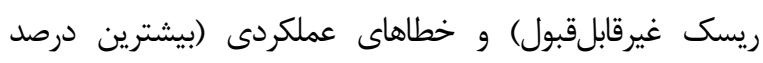
خطاهاى با سطح ريسك ALARP) بايد در اولويت قرار بكيرند.

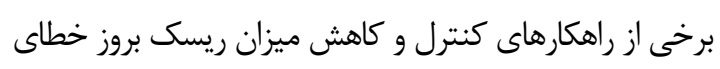

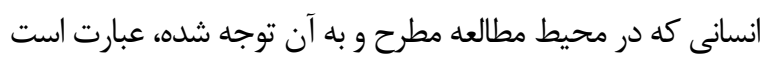

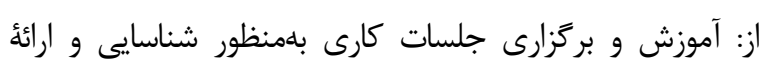

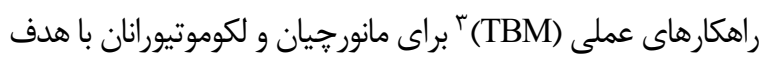

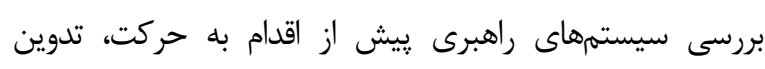

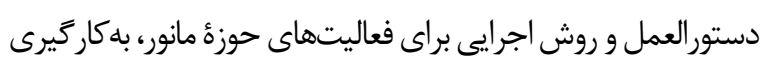

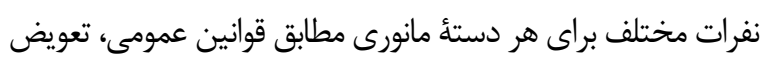
بىسيمهاى معيوب و استفاده از بىسيمهاى باكيفيت، درنظركر مرفتن

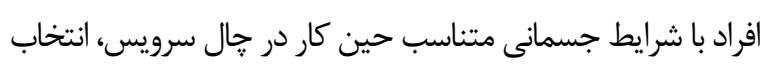
افراد داراى دقت و هوش بالاتر، نصب علائم ايمنى و هشدارى جين،

\section{Tool Box Meeting}




$$
\text { منعارض منافع منابع مالى نوين منابع مالى اين مطالعه توسط نويسندكان تامين شده است. }
$$

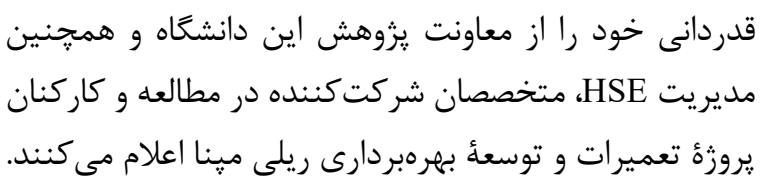

\section{References}

1. Abbassinia M, Kalatpour O, Motamedzade M, Soltanian A, Mohammadfam I. The application of lean production in reducing human error and improving response in emergencies: A case study in a petrochemical industry. Iran J Ergon. ISSN. 2020 Jun 10;2345:5365.

2. Zameni F, Soltanzadeh A, Nasiri P. Designing a conceptual model for the relationship between shift work, job stress, job satisfaction and health: A case study in petrochemical industry. Iran J Ergon. 2018 Oct 31;6(2):64-70. [DOI:10.30699/jergon.6.2.64]

3. Amiri Ebrahimabadi A, Soltanzadeh A, Ghiyasi S. Analysis of Occupational Accidents Based on the Human Factors Analysis and Classification System (HFACS): A Case Study in a Copper Mine. Iran J Ergon. $2020 \quad$ May 10;8(1):12-20. [DOI:10.30699/jergon.8.1.12]

4. Ghasemi F, Kalatpour O, Moghimbeigi A, Mohammadfam I. Selecting strategies to reduce highrisk unsafe work behaviors using the safety behavior sampling technique and Bayesian network analysis. Res. J. Med. Sci . 2017;17(1):372.

5. Mohammadfam I, Eskandari T, Farokhzad M. Evaluation and Analysis of Human Error in the Use of Equipment Using PUEA Technique and Fuzzy Logic. Iran J Ergon. 2018 Oct 10;6(3):21-32. [DOI:10.30699/jergon.6.3.3]

6. Babamiri M, Ghasemi F, Heidari Moghadam R, Derakhshan J, Karimi M. Investigating the working Conditions Using the ILO Checklist Based on the Interventional Approach of Participatory Ergonomics and its Impact on the Quality of Working Life and Musculoskeletal Disorders. Iran J Ergon. 2018 Mar 10;5(4):49-55. [DOI:10.30699/jergon.5.4.49]

7. Mohammadfam I, Saeidi C. Evaluating human errors in cataract surgery using the SHERPA technique. Iran J Ergon. 2015;2(4):41-7.

8. Evans M, He Y, Maglaras L, Janicke H. HEART-IS: A novel technique for evaluating human error-related information security incidents. J. Comput. Secur. 2019 Jan 1;80:74-89. [DOI:10.1016/j.cose.2018.09.002]

9. Zhou JL, Lei Y, Chen Y. A hybrid HEART method to estimate human error probabilities in locomotive driving process. Reliab. Eng. Syst. Saf. 2019 Aug 1;188:80-9. [DOI:10.1016/j.ress.2019.03.001]
10. Reinach S, Viale A. Application of a human error framework to conduct train accident/incident investigations. Accid Anal Prev. 2006 Mar 1;38(2):396406. [DOI:10.1016/j.aap.2005.10.013] [PMID]

11. Morais C, Moura R, Beer M, Patelli E. Analysis and estimation of human errors from major accident investigation reports. ASCE-ASME J Risk Uncert Engrg Sys Part B Mech Engrg. 2020 Mar 1;6(1). [DOI:10.1115/1.4044796]

12. Mohammadfam I, Movafagh M, Soltanian A, Salavati $\mathrm{M}$, Bashirian S. Identification and evaluation of human errors among the nurses of coronary care unit using CREAM techniques. Iran J Ergon. 2014 Jun 10;2(1):2735.

13. Ghasemi F, Mirzaei M, Mahdinia M, Darvishi E, Shahidi R. The role of personal commitment to safety in shaping safety performance of front-line employees: a case study in small manufacturing industries. Iran J Ergon. $\quad 2018 \quad$ Sep 10;6(2):16-23. [DOI:10.30699/jergon.6.2.16]

14. Embrey DE. SHERPA: A systematic human error reduction and prediction approach. InProceedings of the international topical meeting on advances in human factors in nuclear power systems 1986.

15. Embrey D. Application of SHERPA to predict and prevent use error in medical devices. InProceedings of the International Symposium on Human Factors and Ergonomics in Health Care 2014 Jun (Vol. 3, No. 1, pp. 246-253). Sage CA: Los Angeles, CA: SAGE Publications.

16. Mirzaei aliabadi M, Mohammad fam I, Karimi S. Identification and assessment of human errors in blasting operations in Iron Ore Mine using SHERA technique. J. Occup. Hyg. Eng. 2015;2(1):57-65.

17. Ghasemi A, Atabi F, Golbabaei F. Human Error Classification for the Permit to Work System by SHERPA in a Petrochemical Industry. J. Occup. Hyg. Eng. 2015 Dec 10;2(3):66-73.

18. Stanton NA, Baber C. Validating task analysis for error identification: reliability and validity of a human error prediction technique. Iran J Ergon. $2005 \mathrm{Jul}$ 15;48(9):1097-113. [DOI:10.1080/00140130500219726] [PMID] 
19. Harris D, Stanton NA, Marshall A, Young MS, Demagalski J, Salmon P. Using SHERPA to predict design-induced error on the flight deck. Aerosp Sci Technol. $2005 \quad$ Sep 1;9(6):525-32. [DOI:10.1016/j.ast.2005.04.002]

20. Stanton NA, Hedge A, Brookhuis K, Salas E, Hendrick $\mathrm{HW}$, editors. Handbook of human factors and ergonomics methods. CRC press; 2004 Aug 30. [DOI:10.1201/9780203489925]

21. Mortazavi Sb, Mahdavi S, Asilian H, Arghami S, Gholamnia R. Identification and assessment of human errors in srp unit of control room of tehran oil refinery using heist technique (2007).

22. Baysari MT, Caponecchia C, McIntosh AS, Wilson JR. Classification of errors contributing to rail incidents and accidents: A comparison of two human error identification techniques. Saf. Sci. 2009 Aug 1;47(7):948-57. [DOI:10.1016/j.ssci.2008.09.012] 